\title{
BMJ
}

\section{Effectiveness of additional supervised exercises compared with conventional treatment alone in patients with acute lateral ankle sprains: systematic review}

\author{
Rogier M van Rijn, junior researcher, John van Ochten, general practitioner, Pim A J Luijsterburg, senior \\ researcher, Marienke van Middelkoop, senior researcher, Bart W Koes, professor of research in general \\ practice, Sita M A Bierma-Zeinstra, professor in osteoarthritis and related disorders
}

Department of General Practice, Erasmus MC, University Medical Center, PO Box 2040, 3000 CA Rotterdam, Rotterdam, Netherlands

Correspondence to: R M van Rijn r.vanrijn@erasmusmc.nl

Cite this as: $B M J$ 2010;341:C5688 doi:10.1136/bmj.c5688

\section{ABSTRACT}

Objective To summarise the effectiveness of adding supervised exercises to conventional treatment compared with conventional treatment alone in patients with acute lateral ankle sprains.

Design Systematic review.

Datasources Medline, Embase, Cochrane Central Register of Controlled Trials, Cinahl, and reference screening.

Study selection Included studies were randomised controlled trials, quasi-randomised controlled trials, or clinical trials. Patients were adolescents or adults with an acute lateral ankle sprain. The treatment options were conventional treatment alone or conventional treatment combined with supervised exercises. Two reviewers independently assessed the risk of bias, and one reviewer extracted data. Because of clinical heterogeneity we analysed the data using a best evidence synthesis. Follow-up was classified as short term (up to two weeks), intermediate (two weeks to three months), and long term (more than three months).

Results 11 studies were included. There was limited to moderate evidence to suggest that the addition of supervised exercises to conventional treatment leads to faster and better recovery and a faster return to sport at short term follow-up than conventional treatment alone. In specific populations (athletes, soldiers, and patients with severe injuries) this evidence was restricted to a faster return to work and sport only. There was no strong evidence of effectiveness for any of the outcome measures. Most of the included studies had a high risk of bias, with few having adequate statistical power to detect clinically relevant differences.

Conclusion Additional supervised exercises compared with conventional treatment alone have some benefit for recovery and return to sport in patients with ankle sprain, though the evidence is limited or moderate and many studies are subject to bias.

\section{INTRODUCTION}

Lateral ligament ankle sprains are one of the most commonly encountered musculoskeletal injuries, ${ }^{1}$ with up to 23000 and 5000 occurring daily in the United States and the United Kingdom, respectively. ${ }^{12}$ In the Netherlands about 600000 people sustain an ankle injury each year, 120000 of which are the result of sporting injuries, and of these it is estimated that 43000 patients present for medical care. ${ }^{34}$ Each year general practitioners in the Netherlands see around 125000 patients with an ankle sprain, with an incidence of eight per 1000 patients per year. ${ }^{5}$ A recent systematic review evaluated the clinical course of conventionally treated acute ankle sprains and found that at one year followup 5-33\% of the patients still experienced pain and instability, 34\% reported at least one re-sprain, and $15-64 \%$ reported that they had not recovered fully from their initial injury. ${ }^{6}$ Despite the large societal effect of these injuries, and considering the commonly encountered poor clinical course, the optimal treatment and rehabilitation has yet to be established.

As part of a formal rehabilitation protocol, balance training and coordination exercises could reduce proprioceptive deficits, symptoms of giving way, and risk of re-injury and improve postural control..$^{7-9}$ Different reviews have shown that functional treatment of the ankle (defined as the use of elastic bandage, tape, lace-up ankle support, or semi-rigid ankle support) results in a quicker return to sports and work compared with immobilisation, that there is no evidence that surgery is better than functional treatment or immobilisation, and that a semi-rigid ankle support is preferable to the use of elastic bandage or tape. ${ }^{10-12}$

Protection of the ankle by means of functional treatment is needed to avoid stress to the scar tissue in the inflammatory phase of tissue healing. In the subsequent phases, the proliferative phase and the maturation phase, the emphasis lies on the alignment and strengthening of the newly formed collagen fibres. ${ }^{13}$ Physical therapists use this knowledge about tissue healing to construct an exercise programme. ${ }^{14}$ The effectiveness of supervised exercises as administered by a physical therapist, however, is uncertain.

We carried out a systematic review to examine the effectiveness of conventional treatment (non-surgical treatment such as immobilisation, non-supervised 


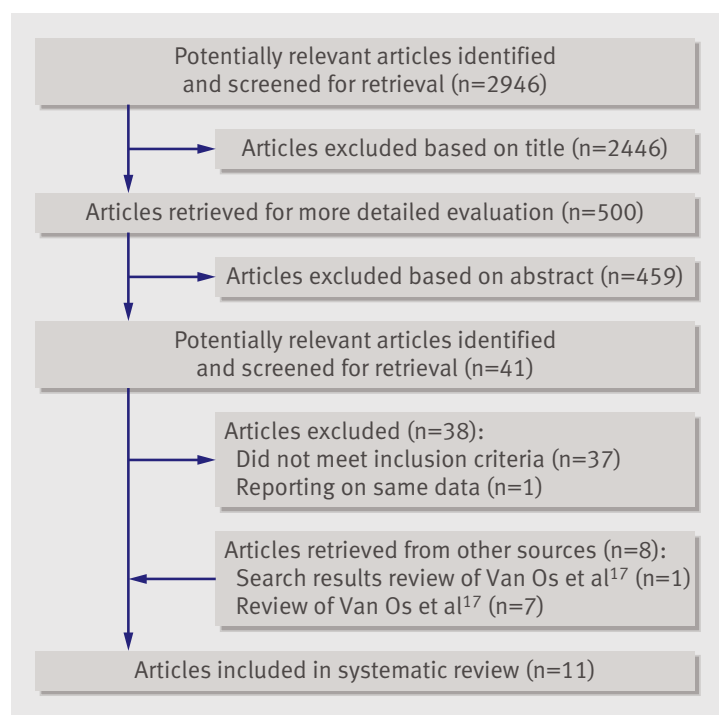

Fig 1| Flow chart of selected articles

treatment involving exercise instructions, or use of external support) combined with supervised exercises compared with conventional treatment alone for the rehabilitation of acute lateral ankle sprains. As the effectiveness can differ between populations ${ }^{1516}$ and can depend on the type of conventional treatment used, the severity of the injury, or the exposure to activities associated with a high risk for (re-) sprains, we also evaluated the added value of supervised exercises in specific populations as well as by type of conventional treatment.

\section{METHODS}

\section{Literature search}

As starting point for our review we identified all references included in an earlier review by van Os et al, ${ }^{17}$ which covered the same topic with a literature search up to March 2004. We then searched Medline, Embase, Cochrane Central Register of Controlled Trials, and CINAHL for March 2004 to July 2010, using the same search strategy (see appendix 1 on bmj.com for details).

Two reviewers (RMvR and PAJL) independently selected the articles, initially based on the title and abstract. For final inclusion the articles had to fulfil all of the following criteria: the adolescent and adult participants had to have an acute lateral ankle sprain, at least one of the treatment options consisted of conventional treatment (defined as either immobilisation, such as in a plaster cast, non-supervised treatment involving exercise instructions, or use of external support), at least one of the treatment options consisted of conventional treatment combined with supervised exercises, and the study design had to be either a randomised controlled trial, quasi-randomised controlled trial, or a controlled clinical trial. We excluded studies of treatment after surgery or treatment of recurrent ankle injuries or chronic instability. The help of a native speaker was obtained for studies published in languages other than English, German, or Dutch. A consensus method was used to resolve disagreements. Finally, the references of all included studies were checked for other possibly relevant articles.

\section{Assessment of risk of bias}

Pairs of reviewers (from RMvR, JvO, and MvM) independently assessed the risk of bias of the included studies using the Cochrane Collaboration's tool (RMvR assessed all studies, except the study of which he is the first author; RMvR was not involved in any decision regarding this trial). ${ }^{18}$ We adapted this tool for our review to give five domains, with 11 items in total (see appendix on bmj.com). Each item was rated as yes, no, or unsure. Disagreements were resolved in a consensus meeting. Studies with six or more points were regarded as having a low risk of bias. The interpretation of the risk of bias tool was pre-tested in two studies that focused on the effectiveness of physical therapy in patients with low back pain.

\section{Data extraction}

One reviewer (RMvR) extracted relevant data from the included studies. For study characteristics, he extracted information on target population (age, sex, setting, injury grade, sample size), treatment, outcome measures, and duration of follow-up. Outcome measures extracted, if present, were pain, instability (feeling of "giving way"), re-sprain, return to sport and work, recovery, and functional scores. In cases of uncertainty about the extracted data from the included studies a second reviewer $(\mathrm{MvM})$ was consulted.

The core findings in each article were expressed as estimates, relative risks, or effect sizes, with corresponding $95 \%$ confidence intervals. When possible, these measures were directly extracted from the article. For articles in which this information was not presented, we calculated these measures if enough data were available. Outcome measures were presented according to follow-up time and therefore grouped into short term (within two weeks of randomisation), intermediate (two weeks to three months of follow-up), and long term (more than three months of follow-up). ${ }^{6}$

\section{Data analysis}

Our main comparison was any conventional treatment versus conventional treatment with additional supervised exercises. Our secondary objective was to evaluate the results of the main comparison in specific vulnerable populations with a high risk for (re-)sprains (such as athletes ${ }^{15}$ ) or with increased risk for slower improvement (such as those with a severe injury ${ }^{16}$ ). Finally, we classified results by type of conventional treatment. When studies were clinically homogenous concerning population, intervention, and outcome measures we statistically pooled data. In cases of clinical heterogeneity we analysed the data using a best evidence synthesis. ${ }^{19}$ This rating system consists of four levels of scientific evidence based on the quality of the studies: strong evidence- provided by generally 
Table 1 Assessment of risk of bias in individual studies on treatment of ankle sprain, with scores per item

\begin{tabular}{|c|c|c|c|c|c|c|c|c|c|c|c|c|}
\hline \multirow[b]{2}{*}{ Authors } & \multirow[b]{2}{*}{$\begin{array}{l}\text { Adequate } \\
\text { randomi- } \\
\text { sation }\end{array}$} & \multirow[b]{2}{*}{$\begin{array}{l}\text { Allocation } \\
\text { concealed }\end{array}$} & \multicolumn{3}{|c|}{ Blinding } & \multirow[b]{2}{*}{$\begin{array}{l}\text { Drop-out } \\
\text { rate } \\
\text { described }\end{array}$} & \multirow[b]{2}{*}{$\begin{array}{c}\text { Intention to } \\
\text { treat } \\
\text { analysis }\end{array}$} & \multirow[b]{2}{*}{$\begin{array}{l}\text { Groups } \\
\text { similar at } \\
\text { baseline }\end{array}$} & \multirow[b]{2}{*}{$\begin{array}{c}\text { Co- } \\
\text { interventions } \\
\text { avoided }\end{array}$} & \multirow[b]{2}{*}{$\begin{array}{l}\text { Compliance } \\
\text { acceptable }\end{array}$} & \multirow{2}{*}{$\begin{array}{l}\text { Timing of } \\
\text { outcome } \\
\text { assessment } \\
\text { similar }\end{array}$} & \multirow[b]{2}{*}{$\begin{array}{l}\text { Total } \\
\text { score }\end{array}$} \\
\hline & & & Patient & $\begin{array}{c}\text { Care } \\
\text { provider }\end{array}$ & $\begin{array}{l}\text { Outcome } \\
\text { assessor }\end{array}$ & & & & & & & \\
\hline Basset et $\mathrm{al}^{22}$ & Yes & Unsure & No & No & No & Yes & Unsure & No & Unsure & Yes & Unsure & 3 \\
\hline Brooks et $\mathrm{al}^{23}$ & Unsure & Unsure & No & No & No & No & Unsure & Unsure & Yes & Unsure & Yes & 2 \\
\hline Holme et $\mathrm{al}^{24}$ & Yes & Unsure & No & No & No & Yes & Yes & Yes & Unsure & Unsure & Yes & 4 \\
\hline Hultman et $\mathrm{al}^{30}$ & No & Unsure & No & No & No & No & Unsure & Unsure & Unsure & Unsure & Yes & 1 \\
\hline Karlsson et $\mathrm{al}^{21}$ & Unsure & Unsure & No & No & No & Yes & Unsure & Unsure & Unsure & Unsure & No & 1 \\
\hline Nilsson ${ }^{25}$ & Unsure & Unsure & No & No & No & Yes & Yes & Unsure & No & Unsure & No & 2 \\
\hline Oostendorp ${ }^{26}$ & Unsure & Unsure & No & No & No & Unsure & Unsure & Unsure & Unsure & Unsure & Yes & 1 \\
\hline Reinhardt et al ${ }^{27}$ & Unsure & Unsure & No & No & No & Yes & Unsure & Unsure & Unsure & Unsure & Yes & 2 \\
\hline Roycroft et al ${ }^{28}$ & Unsure & Unsure & No & No & No & No & Unsure & Unsure & Unsure & Unsure & Yes & 1 \\
\hline van Rijn et $a^{20}$ & Yes & Yes & No & No & No & Yes & Yes & Unsure & Unsure & Yes & Yes & 6 \\
\hline Wester et $\mathrm{al}^{29}$ & Yes & Unsure & No & No & No & No & Unsure & Unsure & Yes & Unsure & Yes & 3 \\
\hline
\end{tabular}

consistent findings in multiple randomised controlled trials assessed as having a low risk of bias; moderate evidence-provided by generally consistent findings in one randomised controlled trial assessed as having a low risk of bias and one or more randomised controlled trials assessed as having a high risk of bias or by generally consistent findings in multiple randomised controlled trials assessed as having a high risk of bias; limited or conflicting evidence - only one randomised controlled trial (either assessed as having low or high risk of bias) or inconsistent findings in multiple randomised controlled trials; and no available evidence - no randomised controlled trials.

\section{RESULTS}

\section{Literature search}

Our search resulted in 2946 potentially relevant articles. From titles and abstract we identified 41 articles. Of these, four articles met our inclusion criteria after we reviewed the full text. Multiple publications were found, reporting on the same data, for van Rijn et al. ${ }^{1620}$ We used information from both publications for the assessment of methodological quality and data extraction but only the first or most prominent publication for citation of these studies. We also went through the original search results of an earlier review by van Os et

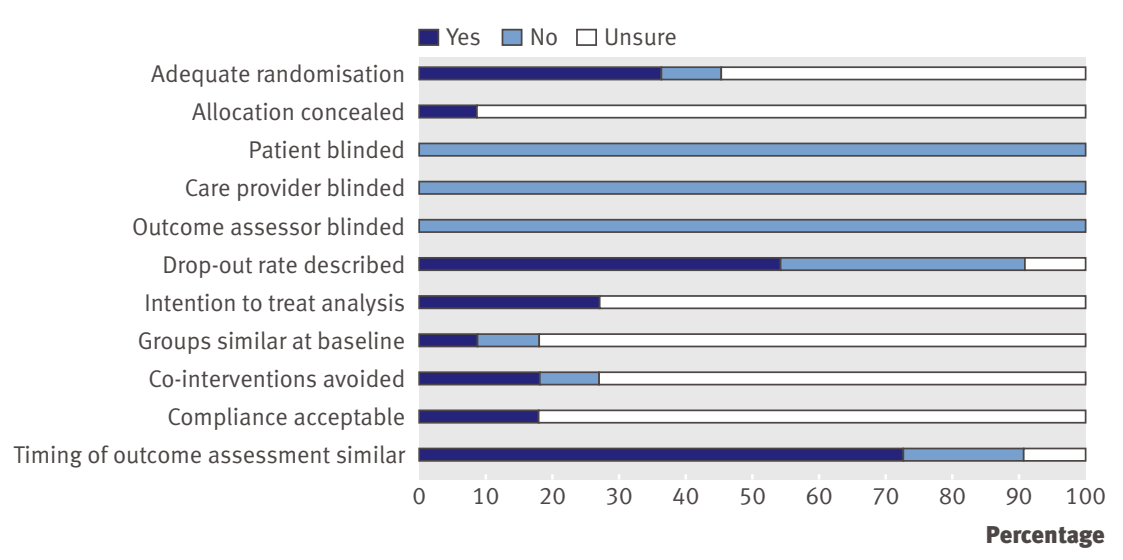

Fig 2 | Assessment of risk of bias $\mathrm{al}^{17}$ on the same topic and found one additional article. ${ }^{21}$ Combined with the articles already included in the review of van Os et al, ${ }^{17}$ we included 11 articles (fig 1).

\section{Assessment of risk of bias}

Figure 2 shows the overall assessment of risk of bias, and table 1 shows the assessment in individual studies. The initial agreement of the reviewers on the total assessment of risk of bias was $80 \%$ (97 of 121 items). Any initial disagreements were solved in a consensus meeting. Ten studies were assessed as having a high risk of bias, ${ }^{21-30}$ and one study was assessed as having a low risk of bias. ${ }^{20}$ The most prevalent shortcomings were found in the items about blinding (patient, care provider, outcome assessor), allocation concealment, and similarity of treatment groups at baseline.

\section{Included studies}

Table 2 shows the characteristics of the included studies. Conventional treatment in the included studies consists of various treatments-namely, no treatment, ice application, partial immobilisation (tape, brace, or bandage), complete immobilisation (plaster cast), a home exercise programme, instructions for early ankle mobilisation, or a combination of these treatments. Supervised exercises consist of visits from a physical therapist in which the patient focused on strength, mobility, and balance exercises whether or not combined with the use of a balance or wobble board. As the included studies were considered too heterogeneous to perform a meta-analysis, we refrained from pooling and performed a best evidence synthesis (table 3). Also, the contrast between the types of conventional treatments was too small to execute an analysis grouped by type of treatment. For that reason, we describe the results of the main comparison per outcome measure but evaluated the results, when possible, by distinguishing between high risk populations. Six studies included a vulnerable population consisting of patients active in sports more than two hours a week, ${ }^{29}$ patients who sustained an ankle sprain during 
Table 2 |Characteristics of included studies physical therapy clinics in middle to low
Author

Basset et $\mathrm{al}^{22}$

47

\section{7 (of 52 enrolled) patients with acute ankle} sprain (first time or recurrent) recruited from 4 socioeconomic suburbs: $60 \%$ male; mean (SD) age 30 (12.4); injury grade: $38 \%$ mild, $51 \%$ moderate, $11 \%$ severe; re-sprain $55 \%$
Conventional treatment

Home based intervention programme. Small home programme of no more than 4 simple activities. Equipmen such as strapping tape, Tubigrip for compression, Theraband resistance bands, and wobble boards. Treatment booklet; information about structure of ankle, ankle sprains, diary grids, progress sheets, adherence enhancing, and 3 treatment phases: 1 -acute (36-48 hours): RICE, and active ankle movements within limits of pain; 2-mobilising (10-14 days): mobilising and strengthening exercises, calf and heel stretches, ankle strapping/taping; 3strengthening (10-14 days): Thera-band resistance, bodyweight resistance in standing, one leg standing, standing on wobble board, weight bearing activities, ankle strapping

Brooks et $\mathrm{al}^{23} \quad 102$ (241) patients with inversion injury, with talar tilt $<15^{\circ}$, who attended local emergency department, age 12-65

Holme et al ${ }^{24} 71$ (92) patients, all recreational athletes, with ankle sprain sustained during sports who attended local emergency department: $62 \%$ male; mean age 26.5 ; injury grade: $30 \%$ mild, $53 \%$ moderate, $17 \%$ severe

Hultman et al ${ }^{30} \quad 65$ (115) with ankle sprain who attended emergency department: $54 \%$ male; mean (range) age 35 (18-65)

Examination of ankle, initial weight unloading with crutches, elastic wrap, and verbal and/or written information from attending physician or nurse about minimal bandage; 2-double Tubigrip support to wear during daytime and advised to remove in bed at night; 3cast, but patients encouraged to bear weight as soon as possible

Pormation regarding early ankle mobilisation, including strength, mobility, and balance exercises mobilisation and early weight bearing, followed by two visits to physiotherapist ( 6 weeks, 3 months): early range of motion training, weight bearing on injured ankle, balance and strength training, instructions for home exercises

Elastic wrapping, partial weight bearing, and crutches unti pain subsided on recreational or competitive level, with ligament ruptures of ankle: $66 \%$ male; mean (range) age 22 (16-38); injury grade: 59\% moderate, $41 \%$ severe

118 (180) patients with injury to lateral ankle Elastic wrapping only $(n=59)$ ligaments (classified as "rupture" or "no rupture") within past 6 hours, who attended local emergency department: $59 \%$ male; mean (range) age 33.6 (15-66)

Oostendorp 24 (24) patients with inversion injury of ankle, sustained during volleyball, basketball, handball, or soccer, who attended physical therapy practices: $67 \%$ male; mean (range) age $22.1(15-30)$

Reinhardt et $\mathrm{al}^{27} 72(80)$ patients, consisting of recruits and professional soldiers, with acute ankle sprain: mean age 22.6

Cryotherapy, compression bandage and minimal weight bearing followed by 6 week tape bandage

Early functional treatment: Aircast brace, non-weight bearing, cryotherapy, elevation for 3-5 days

\section{Supervised treatment}

Clinic based intervention programme. Small home programme of no more than 4 simple activities. Physical therapist treated symptoms, and supervised activities/ exercises of 3 phase physical therapy programme: 1 -acute (36-48 hours): RICE, and active ankle movements within limits of pain; mobilising (10-14 days): 2-mobilising and strengthening exercises, calf and heel stretches, ankle strapping/taping; 3-strengthening (10-14 days): Theraband resistance, bodyweight resistance in standing, one leg standing, standing on wobble board, weight bearing activities, ankle strapping

First day or within 48 hours of presentation: iced foot bath, mobilisation, instruction in normal gait. Second or third visit: wobble board exercises. Treatment considered complete when patient could tolerate 10 minutes on wobble board Information regarding early ankle mobilisation, including strength, mobility, and balance exercises, combined with supervised group physical therapy rehabilitation (1 hour, twice weekly): comprehensive balance exercises on both legs, figure of eight running; standing on balance board and catching ball, standing on outside of feet, standing on inside of feet with open and closed eyes

Examination of ankle, initial weight unloading with crutches, elastic wrap, and verbal and/or written information from attending physician or nurse about mobilisation and early weight bearing, followed by four visits to physiotherapist (baseline, 3 weeks, 6 weeks, 3 months): early range of motion training, weight bearing on injured ankle, balance and strength training, instructions for home exercises

Functional treatment: compression pads, early weightbearing. Range of motion training: dorsal and plantar flexion, supination, proprioceptive training, standing on one leg with eyes closed, walking along zig-zag lines. Strength training: rubber cords, weight boots

Elastic wrapping and cryotherapy combined with physiotherapy starting on 5th day after injury: limbering exercises of ankle, ultrasound treatment to lateral side of ankle, coordination exercises, strengthening exercises of fibular muscles ( $n=59)$. Each session lasted 45 mins and was given daily until patient was symptom free or had received 10 treatments

Cryotherapy, compression bandage, and minimal weight bearing followed by 6 week tape bandage combined with standardised progressive training program (3 physical therapy sessions/week, daily home exercises): stability exercises, disturbance in balance, variation in posture, visual control), isometric strengthening exercises, manual resistance

Early functional treatment: Aircast-brace, non-weight bearing, cryotherapy, elevation for 3-5 days. Six physical therapy sessions: proprioceptive training (balance board, rough terrain), limbering exercises, strengthening exercises, home exercises $(n=47)$

Roycroft et $\mathrm{al}^{28} \quad 43$ (98) patients with inversion injuries of ankle who attended local emergency department: injury grade: $47.5 \%$ mild, $52.5 \%$ moderate

van Rijn et al $102(107)$ patients with acute lateral ankle sprain, who attended GP or local emergency department: $58 \%$ male; mean age 37.0 ; injury grade $42 \%$ mild, $40 \%$ moderate, $4 \%$ severe, $14 \%$ unknown

Wester et $a^{29} \quad 48$ (61) patients, active in sports $>2$ hour/ week, with primary ankle sprain who attended local emergency department: $60 \%$ male; mean (SD) age 25 (7.2); injury grade: moderate
Wool and elastoplasts bandage or plaster of Paris backslab, Immediate active treatment (RICE) and full weight bearing, non-weight bearing $(n=37)$ after 24 hours referred to physical therapy: ultrasonography, taping, Tubigrip support, mobilisation and rehabilitation $(n=43)$

Early ankle mobilisation, home exercises, early weight bearing, and tape, bandage, or brace $(n=53)$ Early ankle mobilisation, home exercises, early weight bearing, and tape, bandage, or brace. Progressive training programme supervised by physiotherapist (max 9 half hour sessions, within 3 months): balance exercises, walking, running, jumping $(n=49)$

Compression bandage for 1 week, leg elevation and Compression bandage for 1 week, leg elevation and immobilisation for 2 days, avoiding activities straining lateral immobilisation for 2 days, avoiding activities straining lateral ligaments, and return to sport activities not permitted until activities of daily living possible without pain.

ligaments, and return to sports activities not permitted until activities of daily living possible without pain, 12 week training programme (15 min/day), with wobble board 
Table $3 \mid$ Results of best evidence synthesis from randomised controlled trials on treatment of ankle sprain

\begin{tabular}{|c|c|c|}
\hline $\begin{array}{l}\text { Outcome and follow- } \\
\text { up* }\end{array}$ & Effectiveness $†$ (risk of bias) & Best evidence synthesis \\
\hline \multicolumn{3}{|l|}{ Pain } \\
\hline Short term & No (high ${ }^{25} 29$ ) & Moderate evidence of no effectiveness \\
\hline Intermediate & Yes $\left(\right.$ high $\left.^{26}\right)$, no $\left(\right.$ high, $^{29}$ low $^{20}$ ) & Conflicting evidence \\
\hline Long term & No (high, ${ }^{25}{ }^{26}$ low $^{20}$ ) & Moderate evidence of no effectiveness \\
\hline \multicolumn{3}{|l|}{ Instability } \\
\hline Short term & - & No available evidence \\
\hline Intermediate & No (high, ${ }^{26} 27$ low $^{20}$ ) & Moderate evidence of no effectiveness \\
\hline Long term & Yes $\left(\right.$ high $\left.^{25}\right)$, no $\left(\right.$ high, $^{26}{ }^{29}$ low $^{20}$ ) & Conflicting evidence \\
\hline \multicolumn{3}{|l|}{ Recovery } \\
\hline Short term & Yes $\left(\right.$ high $\left.^{28}\right)$ & Limited evidence of effectiveness \\
\hline Intermediate & No $\left(\operatorname{low}^{20}\right)$ & Limited evidence of no effectiveness \\
\hline Long term & No $\left(\operatorname{low}^{20}\right)$ & Limited evidence of no effectiveness \\
\hline \multicolumn{3}{|l|}{ Function } \\
\hline Short term & No $\left(\right.$ high $\left.^{22}\right)$, yes $\left(\right.$ high $^{30}$ ) & Conflicting evidence \\
\hline Intermediate & - & No available evidence \\
\hline Long term & No $\left(\right.$ high $^{21}$ ) & Limited evidence of no effectiveness \\
\hline \multicolumn{3}{|l|}{ Re-sprain } \\
\hline Short term & - & No available evidence \\
\hline Intermediate & No $\left(\right.$ high $^{27}$, low $\left.^{20}\right)$ & Moderate evidence of no effectiveness \\
\hline Long term & Yes $\left(\right.$ high $\left.^{24}\right)$, no (high, ${ }^{25}{ }^{29}$ low $^{20}$ ) & Conflicting evidence \\
\hline \multicolumn{3}{|l|}{ Return to work } \\
\hline Short term & NA $\left(\right.$ high $\left.^{2125}\right)$, yes $\left(h^{2} h^{23}{ }^{27}\right)$, no $\left(\right.$ high $\left.^{30}\right)$ & Conflicting evidence \\
\hline Intermediate & No $\left(\right.$ high $^{26}$ ) & Limited evidence of no effectiveness \\
\hline Long term & No $\left(\right.$ high ${ }^{26}$ ) & Limited evidence no effectiveness \\
\hline \multicolumn{3}{|l|}{ Return to sport } \\
\hline Short term & Yes $\left(\right.$ high $\left.^{21}\right)$, NA $\left(\right.$ high $^{27}$ ) & Limited evidence of effectiveness \\
\hline Intermediate & Yes at 6 weeks, no at 12 weeks $\left(\right.$ high $\left.^{26}\right) \ddagger$ & Conflicting evidence \\
\hline Long term & No $\left(\right.$ high ${ }^{26}$ ) & Limited evidence of no effectiveness \\
\hline
\end{tabular}

$\mathrm{NA}=$ not applicable because of incomplete data.

*Short term=up to 2 weeks; intermediate $=2$ weeks to 3 months; long term=more than 3 months.

$\dagger$ Effectiveness of conventional treatment combined with supervised exercises compared with conventional

treatment alone.

$\ddagger$ Study measured return to sport at 6 and 12 weeks, both of which are part of intermediate term follow-up. No differences between treatment groups found at 6 weeks, whereas significant difference in favour of supervised exercises found at 12 weeks. promoted early ankle mobilisation or early weight bearing. Oostendorp also assessed the effect of additional supervised exercises at intermediate followup, ${ }^{26}$ whereas the other studies found no significant difference between treatment groups. Therefore, the evidence of effectiveness is conflicting. None of the studies that described pain as an outcome measure found a significant difference between treatment groups at short term ${ }^{2529}$ and long term ${ }^{202526}$ followup, resulting in moderate evidence of no effectiveness.

In a subgroup of studies of athletes we found conflicting evidence of effectiveness (intermediate term) and moderate evidence of no effectiveness (short and long term). ${ }^{2629}$ There was also limited evidence of effectiveness in patients with severe injuries at intermediate follow-up. ${ }^{20}$

\section{Instability}

Five studies, four with a high risk of bias ${ }^{25-2729}$ and one with a low risk of bias, ${ }^{20}$ presented instability as an outcome measure to evaluate the effectiveness of additional supervised exercises. Four studies use a questionnaire to measure instability or the "feeling of giving way." 20252729 All studies provided the number of patients reporting instability. Conventional treatment was similar in three of five studies. Oostendorp ${ }^{26}$ and Reinhardt et $\mathrm{al}^{27}$ used a more reserved policy in the first week of rehabilitation by prescribing cryotherapy, compression bandage or aircast brace, and minimal weight bearing, whereas the other studies promoted early ankle mobilisation or early weight bearing as much as pain allowed.

We could not calculate relative risks from the study of Wester et $\mathrm{al},{ }^{29}$ though they reported a significant difference in the number of patients with instability at long term follow-up. No differences were found in the other studies concerning instability. ${ }^{202529}$ Therefore the evidence for effectiveness was conflicting at long term follow-up. None of the studies that described instability as an outcome measure found a significant difference between treatment groups at intermediate follow-up, ${ }^{202627}$ resulting in moderate evidence of no effectiveness.

In a subgroup of studies of athletes or soldiers there was moderate evidence of no effectiveness in the intermediate and conflicting evidence of effectiveness in the long term. ${ }^{262729}$ There was limited evidence of effectiveness in patients with severe injuries at intermediate follow-up. ${ }^{20}$

\section{Re-sprain}

Five studies, one with a low risk of bias ${ }^{20}$ and four with a high risk of bias, ${ }^{24252729}$ reported the number of resprains sustained during intermediate and long term follow-up. In three of these studies participants were recreational athletes, patients who were active in sports over two hours a week, and recruits or professional soldiers. ${ }^{242729}$ Conventional treatment was similar in four of five studies. The studies of van Rijn et al, ${ }^{20}$ Holme et al, ${ }^{24}$ Nilsson, ${ }^{25}$ and Wester et al ${ }^{29}$ promoted 
Table $4 \mid$ Results of individual studies with pain as outcome measure classified by duration of follow-up

\begin{tabular}{|c|c|c|c|}
\hline Outcome & $\begin{array}{c}\text { Conventional } \\
\text { treatment }\end{array}$ & $\begin{array}{c}\text { Supervised } \\
\text { treatment }\end{array}$ & $\begin{array}{l}\text { Relative risk or effect size* } \\
\qquad(95 \% \mathrm{Cl})\end{array}$ \\
\hline \multicolumn{4}{|l|}{ Short term } \\
\hline \multicolumn{4}{|l|}{ Nillson ${ }^{25}$} \\
\hline No (\%) with pain at 7 days & $38(64.4)$ & $31(52.5)$ & $0.82(0.60$ to 1.11$)$ \\
\hline \multicolumn{4}{|l|}{ Wester $^{29}$} \\
\hline \multicolumn{4}{|l|}{ No (\%) with pain at 7 days: } \\
\hline At rest & $7(29)$ & $12(50)$ & 1.71 (0.82 to 3.60$)$ \\
\hline Walking & $20(83)$ & $20(83)$ & 1.00 (0.78 to 1.29$)$ \\
\hline Sports & $23(96)$ & $23(96)$ & $1.00(0.89$ to 1.13$)$ \\
\hline
\end{tabular}

\section{Intermediate}

Oostendorp ${ }^{26}$

Mean (SD) pain (VAS 0-100):

\begin{tabular}{|c|c|c|c|}
\hline At 6 weeks & $25(5)$ & $18(7)$ & $1.11 \dagger(0.25$ to 1.97$) \ddagger$ \\
\hline At 12 weeks & $15(7)$ & $9(8)$ & $0.77 \dagger(-0.06$ to 1.60$)$ \\
\hline \multicolumn{4}{|l|}{ van Rijn ${ }^{20}$} \\
\hline \multicolumn{4}{|c|}{ Mean (SD) pain (VAS 0-10) at 3 months: } \\
\hline At rest§ & $0.4(1.0)$ & $0.3(1.2)$ & $0.14 \dagger(-0.28$ to 0.56$)$ \\
\hline Walking flat§ & $0.4(1.0)$ & $0.4(1.3)$ & $0.04 \dagger(-0.38$ to 0.47$)$ \\
\hline Walking rough§ & $1.3(1.7)$ & $0.8(1.3)$ & $0.30 \dagger(-0.13$ to 0.72$)$ \\
\hline \multicolumn{4}{|c|}{ Mean (SD) pain in subgroup AFS $\leq 40$ (severe) at 8 weeks: } \\
\hline At rest & $1.5(2.6)$ & $0.5(1.0)$ & $0.50 \dagger(-0.03$ to 1.03$)$ \\
\hline Walking flat & $1.2(1.9)$ & $0.6(1.2)$ & $0.37 \dagger(-0.16$ to 0.90$)$ \\
\hline Walking rough & $3.1(2.4)$ & $1.7(1.9)$ & $0.64 \dagger(0.10$ to 1.17$) \ddagger$ \\
\hline \multicolumn{4}{|c|}{ Mean (SD) pain in subgroup AFS $>40$ (mild) at 8 weeks: } \\
\hline At rest & $0.6(1.5)$ & $0.2(0.7)$ & $0.31 \dagger(-0.27$ to 0.89$)$ \\
\hline Walking flat & $0.5(1.5)$ & $0.3(0.6)$ & $0.17 \dagger(-0.41$ to 0.75$)$ \\
\hline Walking rough & $1.5(2.3)$ & $1.1(1.7)$ & $0.19 \dagger(-0.39$ to 0.77$)$ \\
\hline
\end{tabular}

Wester $^{29}$

No (\%) with pain:

\begin{tabular}{lccc}
\hline At rest, 6 weeks & $0(0)$ & $1(4)$ & NA \\
\hline At rest, 12 weeks & $1(4)$ & $0(0)$ & NA \\
\hline Walking, 6 weeks & $5(21)$ & $6(25)$ & 1.20 (0.42 to 3.41) \\
\hline Walking, 12 weeks & $1(4)$ & $1(4)$ & 1.00 (0.07 to 15.08) \\
\hline Sports, 6 weeks & $18(75)$ & $18(75)$ & 1.00 (0.72 to 1.39) \\
\hline Sports, 12 weeks & $7(29)$ & $4(17)$ & 0.57 (0.19 to 1.70) \\
\hline
\end{tabular}

Long term

Nillson ${ }^{25}$

No (\%) with pain:

\begin{tabular}{|c|c|c|c|}
\hline At 3-6 months & $19(32.2)$ & $18(30.5)$ & 0.95 (0.56 to 1.62$)$ \\
\hline At 3 years & $8(15.7)$ & $5(9.4)$ & $0.60(0.21$ to 1.72$)$ \\
\hline \multicolumn{4}{|l|}{ Oostendorp ${ }^{26}$} \\
\hline Mean (SD) pain (VAS 0-100) at 24 weeks & $10(6)$ & $6(4)$ & $0.76 \dagger(-0.07$ to 1.59$)$ \\
\hline \multicolumn{4}{|l|}{ van Rijn ${ }^{20}$} \\
\hline \multicolumn{4}{|l|}{ Mean (SD) pain (VAS 0-10) at 12 months: } \\
\hline At rest§ & $0.3(0.8)$ & $0.3(0.9)$ & $0.02 \dagger(-0.44$ to 0.48$)$ \\
\hline Walking flat§ & $0.2(0.7)$ & $0.3(0.9)$ & $-0.10 \dagger(-0.56$ to 0.36$)$ \\
\hline Walking rough§ & $0.8(1.4)$ & $0.9(2.1)$ & $-0.05+(-0.51$ to 0.41$)$ \\
\hline \multicolumn{4}{|c|}{ Mean (SD) pain in subgroup AFS $\leq 40$ (severe) at 12 months: } \\
\hline At rest & $0.4(0.8)$ & $0.3(0.9)$ & $0.12 \dagger(-0.41$ to 0.64$)$ \\
\hline Walking flat & $0.2(0.7)$ & $0.3(1.0)$ & $-0.11 \dagger(-0.64$ to 0.41$)$ \\
\hline Walking rough & $1.0(1.5)$ & $0.9(2.3)$ & $0.05 \dagger(-0.47$ to 0.57$)$ \\
\hline \multicolumn{4}{|l|}{ Mean (SD) pain in subgroup AFS >40 (mild): } \\
\hline At rest & $0.1(0.6)$ & $0.4(0.9)$ & $-0.39+(-0.98$ to 0.19$)$ \\
\hline Walking flat & $0.3(0.8)$ & $0.1(0.5)$ & $0.29 \dagger(-0.29$ to 0.87$)$ \\
\hline Walking rough & $0.8(1.5)$ & $1.0(2.1)$ & $-0.11 \dagger(-0.69$ to 0.47$)$ \\
\hline
\end{tabular}

$\mathrm{NA}=$ not applicable; VAS=visual analogue scale; $\mathrm{AFS}=$ ankle function score.

${ }^{*}$ Effect size $>0$ indicates beneficial effects of supervised treatment; relative risk $<1.0$ indicates beneficial effects of supervised treatment.

†Effect size.

$\ddagger P<0.05$.

§Double publication showed known that data on pain were available at certain follow-up times; data obtained after request to authors. early ankle mobilisation or early weight bearing as much as pain allowed, whereas the study by Reinhardt et $\mathrm{al}^{27}$ prescribed a more preserved policy (cryotherapy, compression bandage, minimal weight bearing). Holme et al found significantly fewer re-sprains in the group treated with early ankle mobilisation combined with supervised balance exercises. ${ }^{24}$ The other studies found no difference between the treatment groups regarding the number of re-sprains, resulting in conflicting evidence for effectiveness at long term follow-up. ${ }^{202529}$ None of the studies showed a difference between treatment groups in the number of resprains reported at intermediate follow-up. Therefore there is moderate evidence of no effectiveness.

In a subgroup of studies in which participants were athletes or soldiers, there was moderate evidence of no effectiveness in the intermediate term and conflicting evidence for effectiveness in the long term. ${ }^{242729}$ There was also limited evidence for no effectiveness of additional supervised exercises at long term follow-up regarding the number of re-sprains in patients with severe injuries. ${ }^{20}$

\section{Recovery}

Two studies described recovery as an outcome measure to determine the effectiveness of additional supervised exercises. ${ }^{2028}$ Recovery was measured with a visual analogue scale ${ }^{20}$ or by calculating the mean period in days to recovery. ${ }^{28}$ Conventional treatment differed between studies: a wool and "elastoplasts" (elasticated) bandage or a plaster of Paris backslab with non-weight bearing ${ }^{28}$ versus early ankle mobilisation and early weight bearing with externally protection of tape, bandage, or brace..$^{20}$

We could not calculate the effect size in the study by Roycroft et al, which had a high risk of bias. ${ }^{28}$ Patients receiving active treatment, however, reported a significantly shorter recovery period than patients receiving conservative treatment at short term follow-up (11.9 $v 18$. 6 days). At intermediate and long term follow-up only one study (with a low risk of bias) reported on recovery but found no differences between treatment groups. ${ }^{20}$ There is therefore limited evidence for effectiveness at short term follow-up and limited evidence for no effectiveness at intermediate and long term follow-up.

Van Rijn and colleagues also performed a subgroup analysis in patients with severe injuries. In this population they found limited evidence for effectiveness at short term follow-up and limited evidence for no effectiveness at intermediate and long term follow-up.

\section{Function}

Three studies, all with a high risk of bias, used some sort of functional score to evaluate the effectiveness of additional supervised exercises. ${ }^{212230}$ Basset et al presented the results of two functional scores: the lower limb task questionnaire and the motor activity scale. ${ }^{22}$ The task questionnaire consisted of two subscales: the recreational activity scale, which measures strenuous activities such as running, jumping and cutting, and 
the activities of daily living scale, which measures less demanding activities such as walking, getting up from a chair, and carrying. The motor activity scale measures motor performance on six activities that involve running, walking, and hopping. Karlsson et al presented a scoring scale for functional results consisting of categories such as instability, pain, swelling, stiffness, work and sport activities, stair climbing, running, and support. ${ }^{21}$ Hultman et al presented the results of the foot and ankle outcome score (FAOS), which is a 42 item questionnaire consisting of five subscales: pain, symptoms, activities of daily living, sports and recreation function, and ankle related quality of life. ${ }^{30} \mathrm{As}$ Hultman et al standardised treatment in both groups after six weeks ${ }^{30}$ we report the results only until that time. In one study participants were patients who were active in sports at a recreational or competitive level. ${ }^{21}$ Conventional treatment differs between the studies: RICE (rest, ice, compression, and elevation) followed by mobilising and strengthening exercises ${ }^{22}$ versus elastic wrapping, partial weight bearing, and crutches until the pain subsided..$^{2130}$

At short term follow-up, Basset and colleagues found no significant differences for both functional scales between the treatment groups. ${ }^{22}$ Though we could not calculate effect sizes from the study of Hultman et al, ${ }^{30}$ patients who received early physiotherapy reported significant improvements on all subscales of the foot and ankle outcome score (FAOS) compared with patients who received conventional treatment at short term follow-up. At long term follow-up, Karlsson et al found no difference in functional results between the two treatment groups. ${ }^{21}$ Consequently, there is conflicting evidence at short term follow-up and limited evidence for no effectiveness at long term follow-up.

The study of Karlsson et al, which is the only study in which the participants were athletes, found no difference in the number of patients with excellent functional results between both treatment groups at long term follow-up. ${ }^{21}$ Therefore, there is limited evidence

\begin{tabular}{|c|c|c|c|}
\hline Outcome & Conventional treatment & Supervised treatment & $\begin{array}{l}\text { Relative risk or effect size } \\
\qquad(95 \% \mathrm{Cl})\end{array}$ \\
\hline \multicolumn{4}{|l|}{ Intermediate } \\
\hline \multicolumn{4}{|l|}{ Oostendorp ${ }^{26}$} \\
\hline \multicolumn{4}{|l|}{ No (\%) with fear of giving way: } \\
\hline At 6 weeks & $8(67)$ & $3(25)$ & $0.38(0.13$ to 1.08$)$ \\
\hline At 12 weeks & $5(42)$ & $2(17)$ & $0.40(0.10$ to 1.67$)$ \\
\hline \multicolumn{4}{|l|}{ Reinhardt2 $^{27}$} \\
\hline No (\%) with instability at 3 months & $5(15)$ & $2(4)$ & $0.28(0.06$ to 1.36$)$ \\
\hline \multicolumn{4}{|l|}{$\operatorname{van} \mathrm{Rijn}^{20}$} \\
\hline No (\%) with instability at 3 months & $32(65)$ & $34(64)$ & $1.02(0.76$ to 1.36$)$ \\
\hline \multicolumn{4}{|c|}{ Mean (SD) instability (VAS 0-10) in subgroup AFS $\leq 40$ (severe) at 8 weeks: } \\
\hline Walking flat & $1.4(1.6)$ & $0.3(0.8)$ & $0.86 \dagger(0.31$ to 1.40$) \ddagger$ \\
\hline Walking rough & $2.8(2.1)$ & $1.6(1.6)$ & $0.63 \dagger(0.10$ to 1.17$) \ddagger$ \\
\hline \multicolumn{4}{|c|}{ Mean (SD) instability (VAS 0-10) in subgroup AFS >40 (mild) at 8 weeks: } \\
\hline Walking flat & $0.7(1.2)$ & $0.4(0.9)$ & $0.27 \dagger(-0.31$ to 0.86$)$ \\
\hline Walking rough & $1.6(2.1)$ & $1.2(1.4)$ & $0.22 \dagger(-0.37$ to 0.80$)$ \\
\hline \multicolumn{4}{|l|}{ Long term } \\
\hline \multicolumn{4}{|l|}{ Nilsson $^{25}$} \\
\hline No (\%) with instability at 3-6 months & $12(20.3)$ & $14(23.7)$ & 1.17 (0.59 to 2.30$)$ \\
\hline No (\%) with instability at 3 years & $12(23.5)$ & $7(13.2)$ & $0.56(0.24$ to 1.31$)$ \\
\hline \multicolumn{4}{|l|}{ Oostendorp ${ }^{26}$} \\
\hline No (\%) with fear of giving way at 24 weeks & $5(42)$ & $1(8)$ & $0.20(0.03$ to 1.47$)$ \\
\hline \multicolumn{4}{|l|}{ van $\operatorname{Rijn}^{20}$} \\
\hline No (\%) with instability at 12 months & $26(53)$ & $30(57)$ & $1.06(0.75$ to 1.52$)$ \\
\hline \multicolumn{4}{|c|}{ Mean (SD) instability (VAS 0-10) in subgroup with AFS $\leq 40$ (severe) at 12 months: } \\
\hline Walking flat & $0.4(0.8)$ & $0.4(1.6)$ & $0.00 \dagger(-0.52$ to 0.52$)$ \\
\hline Walking rough & $1.4(1.5)$ & $1.4(2.5)$ & $0.00 \dagger(-0.52$ to 0.52$)$ \\
\hline \multicolumn{4}{|c|}{ Mean (SD) instability (VAS 0-10) in subgroup with AFS >40 (mild) at 12 months: } \\
\hline Walking flat & $0.3(0.7)$ & $0.5(1.5)$ & $-0.17 \dagger(-0.75$ to 0.41$)$ \\
\hline Walking rough & $0.7(1.3)$ & $1.5(2.6)$ & $-0.39 \dagger(-0.98$ to 0.19$)$ \\
\hline \multicolumn{4}{|l|}{ Wester ${ }^{29}$} \\
\hline No (\%) with instability at 230 days & $6(25)$ & $0(0)$ & NA \\
\hline \multicolumn{4}{|c|}{$\begin{array}{l}\text { VAS=visual analogue scale; AFS=ankle function score. } \\
\text { *Effect size }>\text { indicates beneficial effects of supervised treatment; relative risk }<1.0 \text { indicates beneficial effects of supervised treatment. } \\
\text { †Effect size. } \\
\ddagger \text { P } 0.05 \text {. }\end{array}$} \\
\hline
\end{tabular}


Table 6 | Results of individual studies with re-sprain as outcome measure classified by duration of follow-up

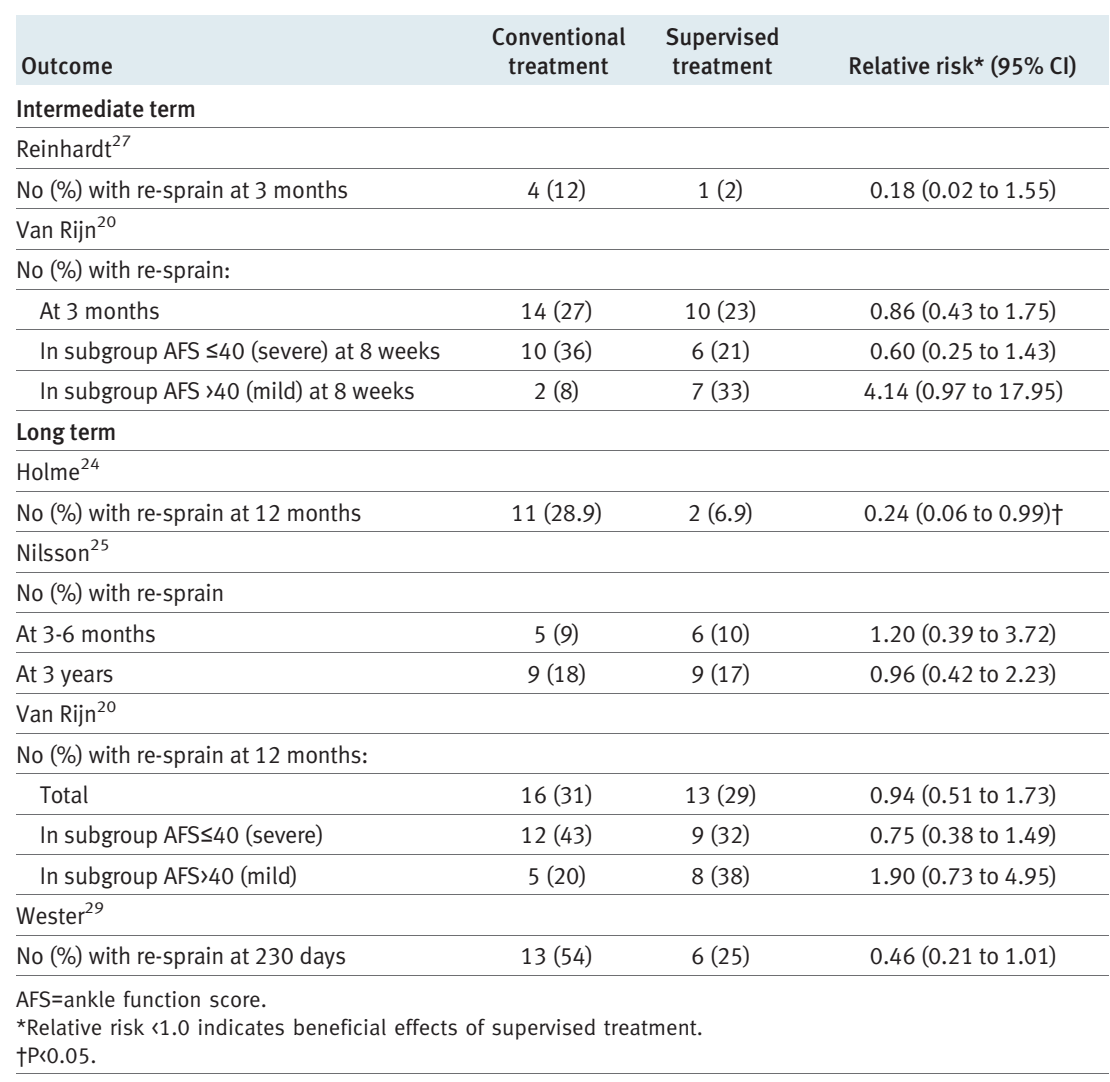

for no effectiveness of additional supervised exercises at long term follow-up in this population.

\section{Return to work}

Seven studies, all with a high risk of bias, used time to return to work as an outcome measure to evaluate the effectiveness of treatment. ${ }^{212325-2730}$ In two of these we could not calculate effect sizes because of insufficient data. ${ }^{2325}$ Conventional treatment differed between the studies. The studies of Oostendorp, ${ }^{26}$ Reinhardt et al, ${ }^{27}$ and Karlsson et $\mathrm{al}^{21}$ prescribed a more reserved policy (cryotherapy, compression bandage, minimal weight bearing until pain subsided). The studies by Nilsson ${ }^{25}$ and Hultman et $\mathrm{al}^{30}$ promoted early ankle mobilisation or early weight bearing as much as pain allowed. In the study of Hultman et al ${ }^{30}$ this treatment was followed by two visits to the physiotherapist at six weeks and three months' follow-up. Brooks et $\mathrm{al}^{23}$ divided conventional treatment into three groups: no treatment or minimal bandaging; elasticated bandaging (Tubigrip); and complete immobilisation in a below the knee plaster of Paris cast.

Three studies included more specific study populations: patients who were active in sports at a recreational or competitive level ${ }^{2126}$ and recruits or professional soldiers. ${ }^{27}$ Reinhardt et $\mathrm{al}^{27}$ and Karlsson et $\mathrm{al}^{21}$ showed a faster return to work or activity in patients who received early functional treatment and supervised balance and strengthening exercises compared with patients who received conventional treatment at short term follow-up. Hultman and colleagues, however, found no differences between treatment groups at short term follow-up concerning return to work. ${ }^{30}$ One study evaluated time to return to work at intermediate and long term follow-up but did not find any difference between treatment groups. ${ }^{26}$ There is therefore conflicting evidence for effectiveness of supervised exercises at short term follow-up in reducing the time to return to work and limited evidence of no effectiveness at intermediate and long term follow-up.

\section{Return to sport}

Three studies, all with a high risk of bias, included time to return to sport as an outcome measure..$^{212627}$ All studies included a more active population — athletes and soldiers-who were more likely to sustain an ankle sprain. Conventional treatment was similar in the three studies. All used a more reserved policy in the first week of rehabilitation by prescribing cryotherapy, compression bandages or aircast brace, and minimal weight bearing (with or without crutches).

At short term follow-up, Karlsson and colleagues reported that patients who received functional treatment, range of motion, and proprioceptive training returned earlier to sports activity than patients who received conventional treatment. ${ }^{21}$ We could not calculate effect sizes for short term follow-up from the study of Reinhardt et al because of incomplete data. ${ }^{27}$ There is therefore limited evidence for the effectiveness of additional supervised exercises at short term follow-up in shortening the time to return to sport. Though the study by Oostendorp found a significant difference between treatment groups at 12 weeks' follow-up (inter mediate), it failed to show differences at six weeks and 24 weeks. ${ }^{26}$ There is therefore conflicting evidence for the effectiveness at intermediate follow-up and limited evidence for no effectiveness at long term follow-up.

\section{DISCUSSION}

In this systematic review of treatment of patients who sustained an acute lateral ligament ankle sprain we found only moderate or limited evidence in favour of adding supervised exercises to conventional treatment compared with conventional treatment alone, according to the outcome measures of recovery and return to sport at short term follow-up. There was no strong evidence for effectiveness of additional supervised exercises for any of the outcome measures.

The evidence for effectiveness of additional supervised exercises is based on a limited number of studies $(\mathrm{n}=11)$, with a maximum of five studies per outcome measure. In these studies conventional treatment was defined as no treatment, ice application, partial or complete immobilisation, home exercise programme, instructions for early ankle mobilisation, or a combination of these treatments. As the effectiveness of additional supervised exercises could depend on the type of conventional treatment, we planned to present the results classified by type. We were unable to do this, however, because of the limited number of studies included and the different types of conventional treatment. 
Table $7 \mid$ Results of individual studies with recovery as outcome measure classified by duration of follow-up

\begin{tabular}{|c|c|c|c|}
\hline Outcome & $\begin{array}{l}\text { Conventional } \\
\text { treatment }\end{array}$ & $\begin{array}{l}\text { Supervised } \\
\text { treatment }\end{array}$ & $\begin{array}{c}\text { Effect size* } \\
(95 \% \mathrm{Cl})\end{array}$ \\
\hline \multicolumn{4}{|l|}{ Short term } \\
\hline \multicolumn{4}{|l|}{ Roycroft $^{28}$} \\
\hline Mean recovery period (days) & 18.6 & 11.9 & NA \\
\hline \multicolumn{4}{|l|}{ Intermediate term } \\
\hline \multicolumn{4}{|l|}{ van Rijn ${ }^{20}$} \\
\hline \multicolumn{4}{|l|}{ Mean (SD) recovery (VAS 0-10): } \\
\hline At 3 months & $7.8(2.4)$ & $8.2(2.4)$ & $0.17(-0.22$ to 0.55$)$ \\
\hline In subgroup AFS $\leq 40$ (severe) at 8 weeks & $6.6(2.0)$ & $7.2(2.1)$ & $0.29(-0.24$ to 0.82$)$ \\
\hline In subgroup AFS >40 (mild) at 8 weeks & $7.7(2.3)$ & $7.0(2.9)$ & $-0.27(-0.85$ to 0.32$)$ \\
\hline \multicolumn{4}{|l|}{ Long term } \\
\hline \multicolumn{4}{|l|}{ van $\operatorname{Rijn}^{20}$} \\
\hline \multicolumn{4}{|l|}{ Mean (SD) recovery (VAS 0-10): } \\
\hline At 12 months & $8.6(1.9)$ & $8.3(2.8)$ & $-0.13(-0.51$ to 0.26$)$ \\
\hline In subgroup AFS $\leq 40$ (severe) at 12 months & $8.7(1.6)$ & $8.4(2.4)$ & $-0.15(-0.67$ to 0.38$)$ \\
\hline In subgroup AFS $>40$ (mild) at 12 months & $8.7(2.1)$ & $9.2(1.9)$ & $0.24(-0.34$ to 0.83$)$ \\
\hline
\end{tabular}

VAS=visual analogue scale; AFS=ankle function score.

${ }^{\star}$ Effect size $>0$ indicates beneficial effects of supervised treatment.

The supervised treatment in the included studies was quite similar and consisted of visits to the physical therapy department, during which rehabilitation focused on strength, mobility, and balance exercises, with or without the use of a balance board. The number of visits and the duration of treatment during follow-up, however, differed between studies, and included a maximum of nine half hour sessions within three months, a 12 week training programme, a six week training programme with three sessions a week, a maximum of 10 sessions of 45 minutes, and a three phase training programme in 14 days.

In addition, studies were heterogeneous regarding the study populations, outcome assessment, and follow-up time. Most of the studies, except one, were assessed as having a high risk of bias. We therefore

Table $8 \mid$ Results of individual studies with function as outcome measure classified by duration of follow-up

\begin{tabular}{|c|c|c|c|}
\hline Outcome & $\begin{array}{l}\text { Conventional } \\
\text { treatment }\end{array}$ & $\begin{array}{l}\text { Supervised } \\
\text { treatment }\end{array}$ & $\begin{array}{l}\text { Effect size or relative risk* } \\
\qquad(95 \% \mathrm{Cl})\end{array}$ \\
\hline \multicolumn{4}{|l|}{ Short term } \\
\hline \multicolumn{4}{|l|}{ Basset $^{22}$} \\
\hline \multicolumn{4}{|l|}{ Mean (SD) scores at 10-14 days: } \\
\hline LLTQ recreational & $8.2(7.2)$ & $12.0(10.1)$ & $-0.43 \dagger(-1.02$ to 0.17$)$ \\
\hline LLTQ ADL & $1.8(3.9)$ & $2.3(3.6)$ & $-0.13 \dagger(-0.72$ to 0.46$)$ \\
\hline Motor activity scale & $5.7(1.1)$ & $5.1(1.3)$ & $0.49 \dagger(-0.11$ to 1.09$)$ \\
\hline \multicolumn{4}{|l|}{ Hultman $^{30}$} \\
\hline FAOS at 6 weeks & NA & NA & NA \\
\hline \multicolumn{4}{|l|}{ Long term } \\
\hline \multicolumn{4}{|l|}{ Karlsson ${ }^{21}$} \\
\hline $\begin{array}{l}\text { No (\%) with excellent results at } \\
12 / 24 \text { months }\end{array}$ & $34(87)$ & $41(91)$ & 0.78 (0.23 to 2.70$)$ \\
\hline \multicolumn{4}{|c|}{$\begin{array}{l}\text { NA=not applicable; } L L T Q=\text { lower limb task questionnaire; } A D L=\text { activities of daily living, FAOS=foot and ankle } \\
\text { outcome score. } \\
\text { *Effect size }>0 \text { indicates beneficial effects of supervised treatment; relative risk }<1.0 \text { indicates beneficial effects } \\
\text { of supervised treatment. } \\
\dagger \text { Effect size. }\end{array}$} \\
\hline
\end{tabular}

refrained from undertaking statistical pooling of the results of the individual studies and conducted a best evidence synthesis.

\section{Risk of bias}

The assessment of risk of bias resulted in 10 of the 11 studies being assessed as having high risk of bias. The threshold to differentiate between low and high risk of bias studies was based on a methodological study of van Tulder et al, ${ }^{31}$ in which they assessed the validity of the Cochrane Collaboration's tool for assessing risk of bias in trials of interventions for back pain. A threshold of $50 \%$ or less was associated with bias; therefore we considered studies with six or more points as having a low risk of bias.

Critical items in the risk of bias assessment were the items on blinding (items 3, 4, and 5), allocation concealment (item 2), and similarity of treatment groups at baseline (item 8). None of the studies scored positively on the items of blinding, probably because of the difficulty of blinding of patients or care providers in physical therapy. Also, in all studies the patient was the outcome assessor so that when patients were not blinded for the intervention, the item on blinding of outcome assessor was automatically scored as negative. Of the 11 studies, 10 were classed as unclear on the items concerning allocation concealment and nine on similarity of treatment groups at baseline. These studies are therefore more susceptible to selection bias, and, as a consequence, this will affect the generalisability of our results. A critical note concerning the risk of bias assessment is that disagreements were resolved in a consensus meeting between the assessors. For more transparency and objectivity it might have been better to consult a third reviewer.

\section{Limitations}

Although we considered only significant differences in the individual studies for the evaluation of the evidence for the effectiveness of additional supervised exercises, there were non-significant differences in favour of the supervised treatment. In these studies, significant differences could be easily missed because of low power (small number of patients); 10 studies did not provide a power analysis. For example, the study of Wester et $\mathrm{al}^{29}$ included only 48 patients and found no difference between treatment groups concerning the number of reported re-sprains. This resulted in a relative risk of 0.46 with a $95 \%$ confidence interval of 0.21 to 1.01 , implying that there is an effect in favour of additional supervised exercises that could become significant if this study was conducted with enough power in a larger population. To confirm such an effect the sample size should be almost doubled. Furthermore, van Rijn and colleagues performed a subgroup analysis of a randomised trial, distinguishing between patients with a mild and a severe sprain based on the ankle function score. ${ }^{1620}$ In patients with severe injuries, they found significant differences in favour of the group who received supervised exercises in addition to usual care. This subgroup analysis, however, was explorative and not predefined. Also, because of the 
Table $9 \mid$ Results of individual studies with return to work and sport as outcome measure classified by duration of follow-up

\begin{tabular}{|c|c|c|c|}
\hline Outcome & $\begin{array}{l}\text { Conventional } \\
\text { treatment }\end{array}$ & $\begin{array}{l}\text { Supervised } \\
\text { treatment }\end{array}$ & $\begin{array}{l}\text { Effect size or relative risk* } \\
\qquad(95 \% \mathrm{Cl})\end{array}$ \\
\hline \multicolumn{4}{|l|}{ Short term } \\
\hline \multicolumn{4}{|l|}{ Brooks $^{23}$} \\
\hline No of days off work & $\begin{array}{c}5.1 / 7.5 / \\
14.0 \dagger\end{array}$ & 6.0 & NA \\
\hline \multicolumn{4}{|l|}{ Hultman $^{30}$} \\
\hline Mean (SD) No of days off work & $6.1(7.4)$ & $4.6(6.1)$ & $0.22 \ddagger(-0.34$ to 0.77$)$ \\
\hline \multicolumn{4}{|l|}{ Karlsson ${ }^{21}$} \\
\hline Mean (SD) No of days of sick & $10.2(6.8)$ & $5.6(4.2)$ & $0.82 \ddagger(0.37$ to 1.27$) \S$ \\
\hline \multicolumn{4}{|l|}{ Nilsson ${ }^{25}$} \\
\hline Mean No of days of sick leave & 12.7 & 11.5 & NA \\
\hline \multicolumn{4}{|l|}{ Reinhardt $^{27}$} \\
\hline Mean (SD) days before return to work & $8.7(3.1)$ & $5.7(3.1)$ & $0.96 \dagger$ (0.49 to 1.43$) \S$ \\
\hline \multicolumn{4}{|l|}{ Intermediate } \\
\hline \multicolumn{4}{|l|}{ Oostendorp $^{26}$} \\
\hline \multicolumn{4}{|l|}{ No (\%) who had returned to work: } \\
\hline At 6 weeks & $10(85)$ & $10(86)$ & $1.00(0.70$ to 1.43$)$ \\
\hline At 12 weeks & $11(88)$ & $11(91)$ & 1.00 (0.79 to 1.27$)$ \\
\hline \multicolumn{4}{|l|}{ Long term } \\
\hline \multicolumn{4}{|l|}{ Oostendorp $^{26}$} \\
\hline No (\%) who returned to work at 24 weeks & $11(91)$ & $11(94)$ & $1.00(0.79$ to 1.27$)$ \\
\hline \multicolumn{4}{|l|}{ Short term } \\
\hline \multicolumn{4}{|l|}{ Karlsson ${ }^{21}$} \\
\hline $\begin{array}{l}\text { Mean (SD) No of days before return to sports } \\
\text { activity }\end{array}$ & $19.2(9.5)$ & $9.6(4.8)$ & $1.29 \dagger(0.82$ to 1.76$) \S$ \\
\hline \multicolumn{4}{|l|}{ Reinhardt $^{27}$} \\
\hline Days before return to sports & 13.8 & 11.7 & NA \\
\hline \multicolumn{4}{|l|}{ Intermediate } \\
\hline \multicolumn{4}{|l|}{ Oostendorp ${ }^{26}$} \\
\hline \multicolumn{4}{|l|}{ No (\%) who returned to sports training: } \\
\hline At 6 weeks & $7(62)$ & $4(30)$ & $0.57(0.22$ to 1.45$)$ \\
\hline At 12 weeks & $11(88)$ & $5(43)$ & $0.45(0.23$ to 0.91$) \S$ \\
\hline \multicolumn{4}{|l|}{ Long term } \\
\hline \multicolumn{4}{|l|}{ Oostendorp ${ }^{26}$} \\
\hline $\begin{array}{l}\text { No (\%) who returned to sports training at } \\
24 \text { weeks }\end{array}$ & $11(96)$ & $9(74)$ & $0.82(0.57$ to 1.18$)$ \\
\hline \multicolumn{4}{|c|}{$\begin{array}{l}\text { *Effect size }>0 \text { indicates beneficial effects of supervised treatment; relative risk }<1.0 \text { indicates beneficial effects } \\
\text { of supervised treatment. } \\
\text { †ln conventional treatment groups: no treatment, no support, or only minimal bandaging/double Tubigrip worn } \\
\text { during day/complete immobilisation of ankle in below knee cast, weight bearing encouraged as soon as } \\
\text { possible (see table 2). } \\
\begin{array}{l}\text { †Effect size. } \\
\text { § } 0.05 .\end{array}\end{array}$} \\
\hline
\end{tabular}

classification into mild and severe injuries, the groups became relatively small, resulting in low power.

\section{Comparison with existing literature}

The limited evidence found for the effectiveness of additional supervised exercises in our review corresponds with findings in studies comparing functional treatment with surgery or immobilisation, or both. In 1965, Freeman showed that external protection combined with mobilisation resulted in a shorter mean time to resolution of symptoms compared with immobilisation and surgery after rupture of the lateral ligament of the ankle. ${ }^{32}$ Recently, Bleakley and colleagues showed that early therapeutic exercises during the first week after an ankle sprain improved ankle function compared with the current best treatment available (applying ice and compression). ${ }^{33}$ Kannus and Renstrom concluded that functional treatment, including protection by tape, bandage, or brace, early weight bearing, range of motion (ROM) exercises, and neuromuscular training resulted in the quickest recovery to full range of motion and faster return to work and physical activity after a grade III ankle sprain compared with surgery or immobilisation. ${ }^{2}$ They found no differences for outcome measures like instability, pain, and swelling. In a more recent review, Kerkhoffs et al showed that functional treatment, which includes elasticated bandages, softcast, tape, or orthosis with associated coordination training, resulted in improved outcomes compared with immobilisation alone. ${ }^{10}$ However, they did not differentiate between supervised and non-supervised treatment as in our present review.

The effectiveness of additional supervised exercises in a more specific population was restricted to moderate or limited evidence concerning the outcomes of return to work and return to sport. There were indications from the individual studies included that more specific groups of patients might benefit to a greater extent from participation in an additional supervised exercise programme. Oostendorp reported significantly less pain at six week follow-up in favour of the supervised exercise group in participants who sustained their ankle sprain during volleyball, basketball, handball, or soccer. ${ }^{26}$ In the study by Holme and colleagues, patients who sustained their ankle sprain during sports and received supervised treatment reported significantly fewer re-sprains at 12 month follow-up compared with the conventional treatment group. ${ }^{24}$ Furthermore, in the study of van Rijn and colleagues, patients with a severe injury who received additional supervised exercises showed significantly less instability at eight week follow-up compared with the conventional treatment group. ${ }^{20}$ More high quality randomised controlled trials are needed to evaluate the effectiveness of additional supervised exercises in more defined subgroups such as athletes and patients with severe injuries.

\section{Conclusions}

In conclusion, we found moderate or limited evidence of effectiveness in favour of additional supervised exercises compared with conventional treatment alone, according to the outcome measures of recovery and return to sport at short term follow-up. We did not find strong evidence for any of the outcome measures. In a more specific population - athletes and soldiers - there was limited to moderate evidence that supervised treatment leads to an earlier return to work and return to sports. Furthermore, there was limited evidence for the effectiveness of supervised treatment in addition to conventional treatment in patients with severe injuries. There were, however, only a few studies, most were assessed as having high risk of bias, and most were lacking power. High quality randomised controlled trials, concentrating on the effectiveness of additional supervised treatment in specific study populations such as athletes and patients with severe injuries, are required. 


\section{WHAT IS ALREADY KNOWN ON THIS TOPIC}

Lateral ligament ankle sprains are one of the most commonly encountered musculoskeletal injuries

Balance training and coordination exercises could reduce proprioceptive deficits, symptoms of giving way, and risk of re-injury and improve postural control

\section{WHAT THIS STUDY ADDS}

There is moderate or limited evidence of effectiveness in favour of additional supervised exercises compared with conventional treatment alone, according to the outcome measures of recovery and return to sport at short term follow-up

There was no strong evidence of effectiveness for any of the outcome measures

In more specific populations, such as athletes and soldiers, there was limited to moderate evidence of effectiveness ligament complex of the ankle in adults. Cochrane Database Syst Rev 2002;3:CD000380.

12 Kerkhoffs GM, Struijs PA, Marti RK, Assendelft WJ, Blankevoort L, van Dijk CN. Different functional treatment strategies for acute lateral ankle ligament injuries in adults. Cochrane Database Syst Rev 2002;3:CD002938.

13 Mattacola CG, Dwyer MK. Rehabilitation of the ankle after acute sprain or chronic instability. J Athl Train 2002;37:413-29.

14 Van der Wees PJ, Lenssen AF, Feijts YAEJ, Bloo H, van Moorsel SR, Ouderland R, et al. The Royal Dutch Society of Physiotherapists (KNGF) practice guideline "ankle injury." Royal Dutch Society of Physiotherapists, 2006.

15 Fong DT, Hong Y, Chan LK, Yung PS, Chan KM. A systematic review on ankle injury and ankle sprain in sports. Sports Med 2007;37:73-94.

16 Van Rijn RM, van Heest JA, van der Wees P, Koes BW, Bierma-Zeinstra SM. Some benefit from physiotherapy intervention in the subgroup of patients with severe ankle sprain as determined by the ankle function score: a randomised trial. Aust J Physiother 2009;55:107-13.

17 Van Os AG, Bierma-Zeinstra SM, Verhagen AP, de Bie RA, Luijsterburg PA, Koes BW. Comparison of conventional treatment and supervised rehabilitation for treatment of acute lateral ankle sprains: a systematic review of the literature. J Orthop Sports Phys Ther 2005;35:95-105.

Contributors: RMvR performed the literature search, selected articles for inclusion, extracted the data, assessed the risk of bias, and performed the analysis. JVO and MvM assessed the risk of bias. PAJL selected articles fo inclusion. BWK and SMAB-Z supervised the study, All authors wrote the article. RMvR is guarantor.

Funding: This study was funded by the Department of General Practice, Erasmus MC University Medical Center.

Competing interests: All authors have completed the Unified Competing Interest form at www.icmje.org/coi_disclosure.pdf (available on request from the corresponding author) and declare: no support from any institution for the submitted work; no financial relationships with any institutions that might have an interest in the submitted work in the previous 3 years; no other relationships or activities that could appear to have influenced the submitted work.

Ethical approval: Not required.

Data sharing: No additional data available.

1 Pijnenburg AC, Van Dijk CN, Bossuyt PM, Marti RK. Treatment of ruptures of the lateral ankle ligaments: a meta-analysis. J Bone Joint Surg Am 2000;82:761-73.

2 Kannus P, Renstrom P. Treatment for acute tears of the lateral ligaments of the ankle. Operation, cast, or early controlled mobilization. J Bone Joint Surg Am 1991;73:305-12.

3 Goudswaard AN, Thomas S, van den Bosch WJHM, van Weert HCPM, Geijer RMM. The Dutch College of General Practitioners (NHG) practice guideline "ankle sprains." 2000. http://nhg.artsennet.nl/ upload/104/guidelines2/E04.htm

4 Schmikli SL, Schoots W, de Wit MJP. Sportblessure het totale speelveld. Kerncijfers en trends van sportblessures in Nederland 1997-2002. NOC*NSF Arnhem

2004 (publicatienummer NOC*NSF 639).

5 Van der Linden MW, Westert GP, de Bakker DH, Schellevis FG. Tweede Nationale Studie naar ziekten en verrichtingen in de huisartspraktijk. Klachten en aandoeningen in de bevolking en in de huisartspraktijk. Utrecht/Bilthoven: NIVEL/RIVM 2004.

6 Van Rijn RM, van Os AG, Bernsen RM, Luijsterburg PA, Koes BW, Bierma-Zeinstra SM. What is the clinical course of acute ankle sprains? A systematic literature review. Am J Med 2008;121:324-31 e6.

7 Freeman MA, Dean MR, Hanham IW. The etiology and prevention of functional instability of the foot. / Bone Joint Surg Br 1965;47:678-85.

8 McKeon PO, Hertel J. Systematic review of postural control and lateral ankle instability. Part II: is balance training clinically effective? J Athl Train 2008;43:305-15.

9 Rozzi SL, Lephart SM, Sterner R, Kuligowski L. Balance training for persons with functionally unstable ankles. J Orthop Sports Phys The 1999;29:478-86.

10 Kerkhoffs GM, Rowe BH, Assendelft W], Kelly K, Struijs PA, van Dijk CN. Immobilisation and functional treatment for acute latera ankle ligament injuries in adults. Cochrane Database Syst Rev 2002;3:CD003762.

11 Kerkhoffs GM, Handoll HH, de Bie R, Rowe BH, Struijs PA. Surgical versus conservative treatment for acute injuries of the lateral
18 Higgins JPT, Green S, eds. Cochrane handbook for systematic review of interventions. Version 5.0.1 [updated September 2008]. Cochrane Collaboration 2008. www.cochrane-handbook.org.

19 Van Tulder MW, Esmail R, Bombardier C, Koes BW. Back schools for non-specific low back pain. Cochrane Database Syst Rev 2000;2:CD000261.

20 Van Rijn RM, van Os AG, Kleinrensink GJ, Bernsen RM, Verhaar JA Koes BW, et al. Supervised exercises for adults with acute latera ankle sprain: a randomised controlled trial. Br / Gen Pract 2007;57:793-800.

21 Karlsson J, Eriksson BI, Sward L. Early functional treatment for acute ligament injuries of the ankle joint. Scand J Med Sci Sports 1996;6:341-5

22 Bassett SF, Prapavessis H. Home-based physical therapy intervention with adherence-enhancing strategies versus clinicbased management for patients with ankle sprains. Phys Ther 2007;87:1132-43.

23 Brooks SC, Potter BT, Rainey JB. Treatment for partial tears of the lateral ligament of the ankle: a prospective trial. $B M J$ 1981;282:606-7.

24 Holme E, Magnusson SP, Becher K, Bieler T, Aagaard P, Kjaer M. The effect of supervised rehabilitation on strength, postural sway, position sense and re-injury risk after acute ankle ligament sprain. Scand I Med Sci Sports 1999;9:104-9.

25 Nilsson S. Sprains of the lateral ankle ligaments. J Oslo City Hosp 1983;33:13-36.

26 Oostendorp R. Functionele instabiliteit na het inversietrauma van enkel en voet: een effectonderzoek pleisterbandage versus pleisterbandage gecombineerd met fysiotherapie. [Functional instability after ankle sprains; a trial of taping versus taping and exercise]. Geneeskd Sport 1987;20:45-55.

27 Reinhardt C, Tiedemann v. Propriorezeptives Training bei Distorsionen des OSG als Beitrag zur Sekundarprohylaxe und früheren Wiedereingliederung. [Proprioreceptive training in ankle sprains can contribute to secondary prophylaxis and earlier reintegration]. Dtsch Z Sportmed 1999;50:89-91.

28 Roycroft S, Mantgani AB. Treatment of inversion injuries of the ankle by early active management. Physiotherapy 1983;69:355-6.

29 Wester JU, Jespersen SM, Nielsen KD, Neumann L. Wobble board training after partial sprains of the lateral ligaments of the ankle: a prospective randomized study. J Orthop Sports Phys Ther 1996;23:332-6.

30 Hultman K, Faltstrm A, Oberg U. The effect of early physiotherapy after an acute ankle sprain. Adv Physiother 2010;12:65-73.

31 Van Tulder MW, Suttorp M, Morton S, Bouter LM, Shekelle P. Empirical evidence of an association between internal validity and effect size in randomized controlled trials of low-back pain. Spine (Phila Pa 1976) 2009;34:1685-92.

32 Freeman MA. Treatment of ruptures of the lateral ligament of the ankle. J Bone Joint Surg Br 1965;47:661-8.

33 Bleakley CM, O'Connor SR, Tully MA, Rocke LG, Macauley DC, Bradbury I, et al. Effect of accelerated rehabilitation on function after ankle sprain: randomised controlled trial. BMJ 2010;340:c1964.

Accepted: 25 August 2010 